\title{
Study of the Mechanism Involved in Angiogenesis and Synovial Cell Proliferation in Human Synovial Tissues of Patients with Rheumatoid Arthritis Using SCID Mice
}

\author{
Masakazu Nagashima, Hidekazu Tanaka, Hiroshi Takahashi, Akitoshi Tachihara, \\ Katsunao Tanaka, Toshiyuki Ishiwata, Goro Asano, and Shinichi Yoshino \\ Department of Joint Disease and Rheumatism (MN, HT, HT, AT, SY), Nippon Medical School, Immunology \\ Research Laboratory (KT), Taiho Pharmaceutical Company Ltd., and Department of Pathology (TI, GA), Nippon \\ Medical School, Tokyo, Japan
}

\begin{abstract}
SUMMARY: To examine whether synovial cell proliferation is due to angiogenesis, we studied the relationship between the inhibition of synovial cell proliferation and an angiogenesis inhibitor, TNP-470, in human synovial tissues. Human synovial tissues were implanted into the back of SCID mice (SCID-HuAg mice). Sixteen mice were divided into two groups of eight mice each: the untreated group (vehicle group) and the TNP-470-treated group that received a dose of $10 \mathrm{mg} / \mathrm{kg}$ body weight by subcutaneous injection. The number of blood vessels and synovial lining cells clearly increased in the vehicle group, but the number of synovial lining cells clearly decreased and the blood vessels were hardly detected in the TNP-470 group. Immunohistochemically, cells that stained positively for the anti-proliferating cell nuclear antigen (PCNA) mAb were abundant in synovial lining cells and endothelial cells in synovial tissues. Cells that stained positively for the anti-CD34 polyclonal antibody were abundant in the endothelial cells in the vehicle group, but these positively stained cells were hardly detected in the TNP-470 group. The PCNA positivity ratio in the vehicle group was $0.64 \pm 0.019$, whereas that in the TNP-470 group was $0.199 \pm 0.007$. The numbers of cells that stained positively for anti-CD34 polyclonal antibody were $242 \pm 13.4$ in the vehicle group and $153 \pm$ 6.73 in the TNP-470 group per 10 microscopic fields. Cells that stained positively for anti-mouse CD31 mAb were mainly localized in the synovial lining, but invaded the subsynovial lining layer in human synovial tissues. On the other hand, cells that stained positively for anti-human CD31 mAb were mainly localized in the subsynovial lining layer. We found that endothelial cell proliferation is dependent on angiogenesis based on the result that angiogenesis and synovial cell proliferation were inhibited by treatment with TNP-470. (Lab Invest 2002, 82:981-988).
\end{abstract}

$T \mathrm{n}$ recent years, it has become clear that angiogen1 esis is important not only in physiologic processes such as embryonic development, wound healing, and organ and tissue regeneration, but also in tumor progression and metastasis (Hanahan and Folkman, 1996). Physiologic angiogenesis is a regulated, selflimiting process, whereas pathologic angiogenesis is critical for pannus formation in rheumatoid arthritis (RA), such as diabetic retinopathy, solid tumor growth, psoriasis, and scleroderma (Hanahan and Folkman, 1996; Koch, 1998). Therefore, we consider several potential mechanisms involved in anti-angiogenesis treatment in RA patients: first, decreasing nutrient supply to tumor-like synovia; second, inhibiting leukocyte adhesion and migration by decreasing endothelial cell surface area; and third, decreasing chemokine

\section{DOI: 10.1097/01.LAB.0000022220.44511.40}

Received December 6, 2001.

This work was supported by a Grant-in-Aid for Scientific Research from the Ministry of Education, Culture, Sports, Science, and Technology of Japan. Address reprint requests to: Dr. Shinichi Yoshino, Department of Joint Disease and Rheumatism, Nippon Medical School, 1-1-5 Sendagi, Bunkyo-ku, Tokyo, 113-8603, Japan.E-mail:n7148@nms.ac.jp and cytokine production by activated endothelial cells (Firestein, 1999).

A number of angiogenic growth factors are involved in the neovascularization process in the RA joint. We have clarified that the vascular endothelial growth factor (VEGF) and basic-fibroblast growth factor (bFGF) are expressed and localized in synovial tissues from RA patients and that their expression level is significantly higher than that from osteoarthritis (OA) patients (Nagashima et al, 1995). VEGF and b-FGF levels in serum and joint fluids from patients with RA are significantly higher than those from OA and nonRA patients. On the other hand, the levels of endostatin, an angiogenesis inhibitor, in the serum and joint fluids from RA and OA patients and nonRA patients were not significantly different (Nagashima et al, 2000).

These results indicate the occurrence of angiogenesis in RA patients due to an imbalance between angiogenic growth factors and angiogenesis inhibitors. However, it is not clear whether angiogenesis contributes to the proliferation of synovial lining cells. Therefore, we investigated whether synovial cell proliferation is inhibited by an angiogenesis inhibitor, TNP-470 (AGM-1470), using human synovial tissues engrafted into the severe combined immunodefi- 
ciency disease (SCID) mouse. The SCID mouse, which has defects in both humoral and cell-mediated immunities, can serve as a recipient of grafts derived from numerous human tissues (Geiler et al, 1994; Jorgensen et al, 1996; Matsuno et al, 1998; Rendt et al, 1993; Sack et al, 1994, 1996).

TNP-470 is a potent angiogenesis inhibitor derived from fumagillin, a naturally occurring fungal product (Ingber et al, 1990) and a selective inhibitor of in vitro b-FGF-stimulated endothelial cell proliferation, endothelial cell migration, and capillary tube formation (Brem and Folkman, 1993). On the other hand, TNP470 generally amplifies human $\mathrm{T}$ cell activation through induction of nuclear factor- $\kappa \mathrm{B}$ and nuclear factor-AT, and B cell proliferation through its action on $T$ cells (Locigno et al, 2000). To examine whether synovial cell proliferation is induced by angiogenesis, we studied the relationship between the inhibition of synovial cell proliferation and TNP-470 in RA patients by immunohistochemistry of human synovial tissues that have been engrafted into the SCID mouse (SCIDHuAg mouse) (Matsuno et al, 1998).

\section{Results}

\section{Histologic and Immunohistochemical Observation at} Various Times after Implantation

Histologic findings by hematoxylin-eosin (HE) and immunohistochemical staining using the anti-human CD34 polyclonal antibody (pAb) performed four times $(1,2,4$, and 6 weeks after implantation in the untreated group, vehicle group) showed that angiogenesis and synovial lining cell proliferation in the tissues were most distinctly observed at 2 weeks after implantation, compared with those at 1,4 , and 6 -weeks after implantation (Fig. 1).

\section{Histologic and Immunohistochemical Observation in Vehicle Group and TNP-470 Group}

On observing synovial tissues that were HE stained 2 weeks after implantation, synovial lining cells were found to proliferate and pile up, and in the sublining layer, the number of blood vessels clearly increased in the vehicle group. On the other hand, the number of synovial lining cells clearly decreased and the blood vessels were hardly detected in the TNP-470 treated group (TNP-470 group). Immunohistochemically, cells that stained positively for the anti-proliferating cell nuclear antigen (PCNA) mAb were abundant in synovial lining cells and endothelial cells in synovial tissues. Cells that stained positively for anti-CD34 pAb were abundantly localized in the endothelial cells in the vehicle group, but these positively stained cells were hardly detected in the TNP-470 group (Fig. 2).

\section{Immunohistochemical Analysis in Vehicle Group and TNP-470 Group}

To investigate how synovial cells proliferate in the two groups 2 weeks after implantation, we counted the number of cells that stained positively for anti-PCNA mAb per 1,000 each of the synovial lining cells and endothelial cells. The PCNA positivity ratio in the vehicle group was $0.64 \pm 0.019$, but that in the TNP-470 group significantly decreased to $0.199 \pm$ 0.007 (Fig. 3).

Next, cells that stained positively for anti-CD34 pAb were counted to determine the number of blood vessels. The numbers of positively stained cells were $242 \pm 13.4$ in the vehicle group and $153 \pm 6.73$ in the TNP-470 group per 10 microscopic fields. There was a significant difference between the vehicle group and the TNP-470 group (Fig. 4). Similar to the case of cell proliferation, the number of blood vessels in the vehi-
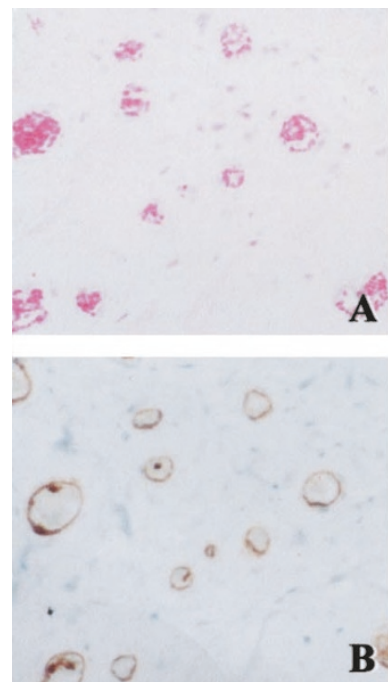
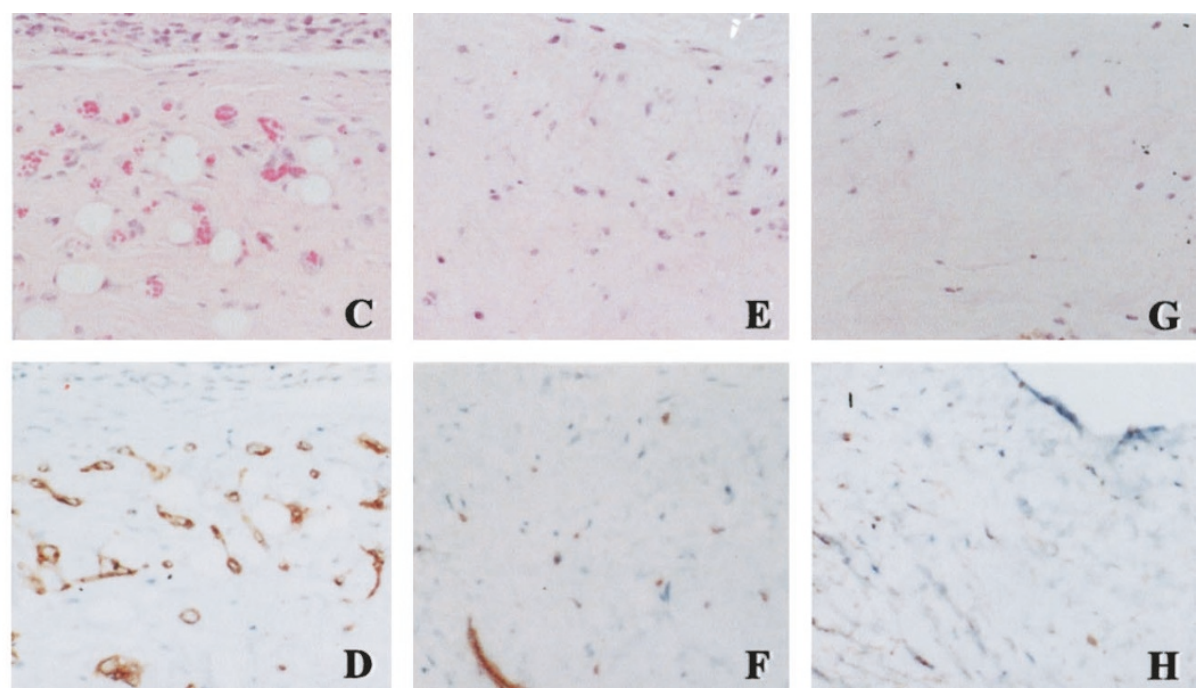

Figure 1.

Hematoxylin-eosin and immunohistochemical staining with anti-CD 34 polyclonal antibody (pAb) in SCID-HuAg mice from vehicle group 1, 2, 4, and 6 weeks after implantation. Endothelial cells that stained positively for $\operatorname{CD} 34 \mathrm{pAb}(\mathrm{B}, \mathrm{D}, \mathrm{F}$, and $\mathrm{H})$. Angiogenesis and synovial cell proliferation were most distinctly observed 2 weeks after implantation. $A$ and $B, C$ and $D, E$ and $F$, and $G$ and $H$ show hematoxylin-eosin (HE) staining and immunohistochemical staining for CD 34 pAb in serial sections $1,2,4$, and 6 weeks after implantation, respectively. Original magnification $(\mathrm{A}$ to $\mathrm{H}), \times 160$. 

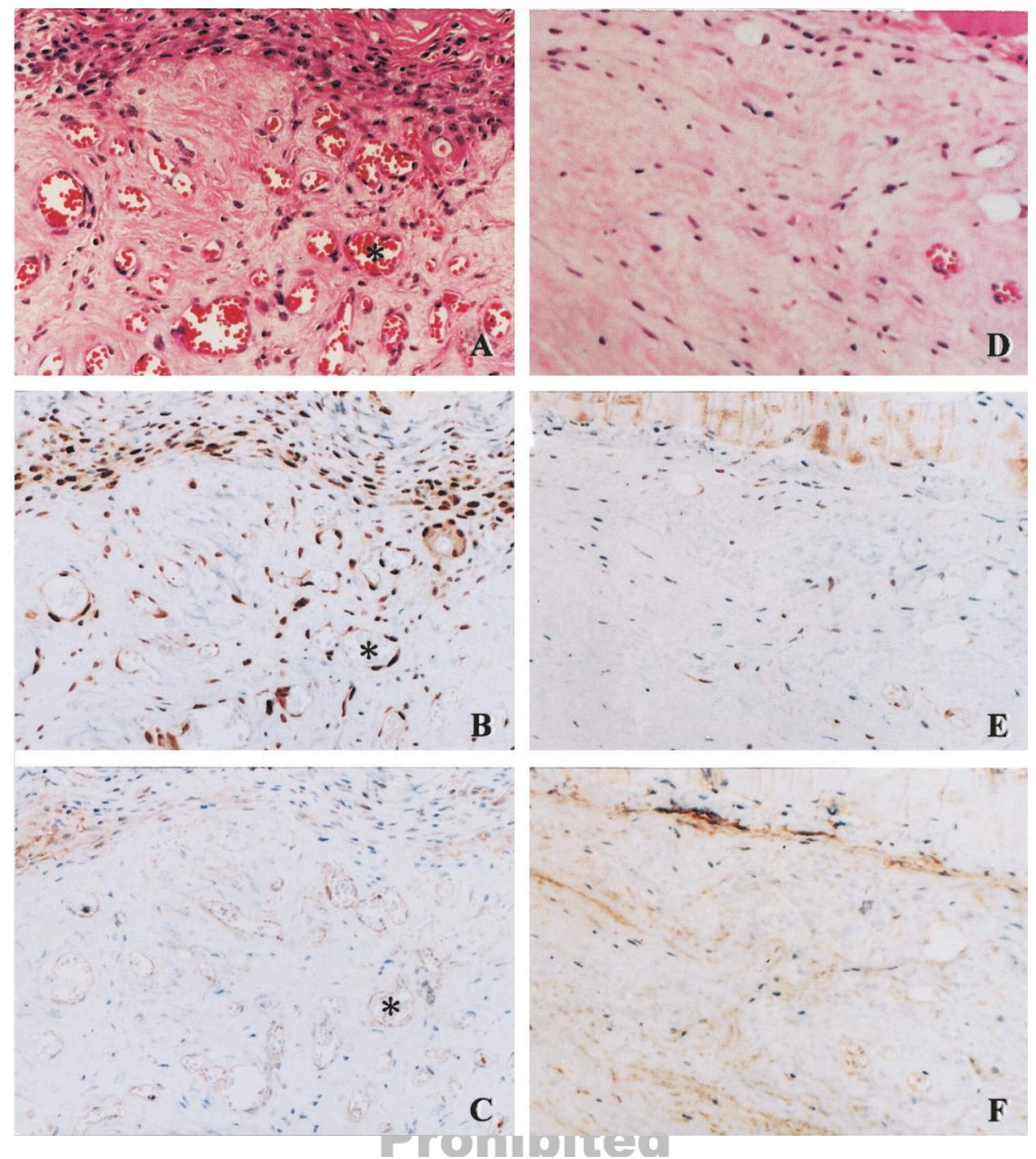

\section{Figure 2.}

Histologic and immunohistochemical findings for proliferating cell nuclear antigen (PCNA) monoclonal and CD34 pAbs in SCID-HuAg mice from vehicle and TNP-470 groups 2 weeks after implantation. A to C show HE staining (A), and immunohistochemical staining for PCNA (B), and CD34 (C) antibodies in serial sections from the vehicle group. D to $F$ show HE staining (D), and immunohistochemical staining for PCNA (E) and CD34 (F) antibodies in serial sections from the TNP-470 group. Cells that show positive staining for PCNA and CD34 antibodies are detected in synovial lining cells and endothelial cells from the vehicle group, but these positively stained cells are hardly detected in synovial lining cells and endothelial cells from the TNP-470 group. Original magnification (A to F), $\times 160 .{ }^{*}$ indicates blood vessel.

cle group was higher than that in the TNP-470 group 2 weeks after implantation.

\section{Human b-FGF and VEGF Analyses in Vehicle Group and TNP-470 Group}

Blood samples were obtained from all of the 16 SCID mice from the two groups that were killed 2 weeks after implantation. The human b-FGF levels in four of the eight peripheral blood samples from the vehicle group were below the detection limit that was deter- mined by dilution using an enzyme-linked immunosorbent assay (ELISA) kit according to the manufacturer's instructions $(<0.6308 \mathrm{pg} / \mathrm{ml})$. The human b-FGF levels of the other four samples were found to range from 1.06 to $5.41 \mathrm{pg} / \mathrm{ml}(2.81 \pm 2.23 \mathrm{pg} / \mathrm{ml})$. On the other hand, the human b-FGF levels in five of the eight samples from the TNP-470 group were below the detection limit $(<0.6308 \mathrm{pg} / \mathrm{ml})$. The human b-FGF levels of the other three cases were found to range from 0.91 to $1.81 \mathrm{pg} / \mathrm{ml}(1.36 \pm 0.64 \mathrm{pg} / \mathrm{ml})$. However, 


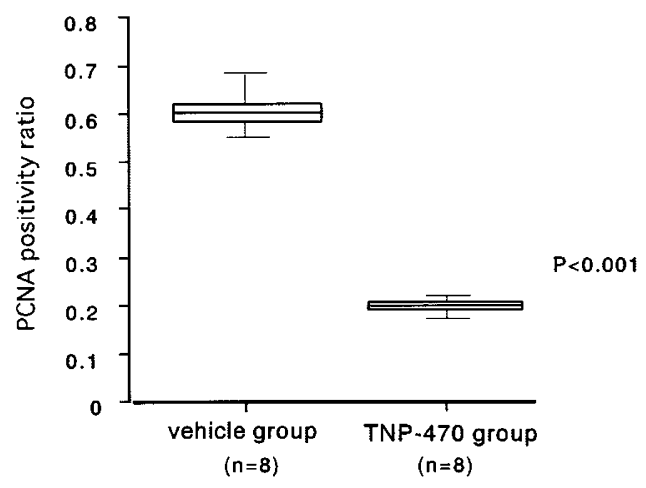

Figure 3.

PCNA positivity ratios in vehicle group and TNP-470 group 2 weeks after implantation. Positivity ratio is calculated and expressed as the number of cells that stained positively for the anti-PCNA mAb per 1,000 synovial cells and endothelial cells.

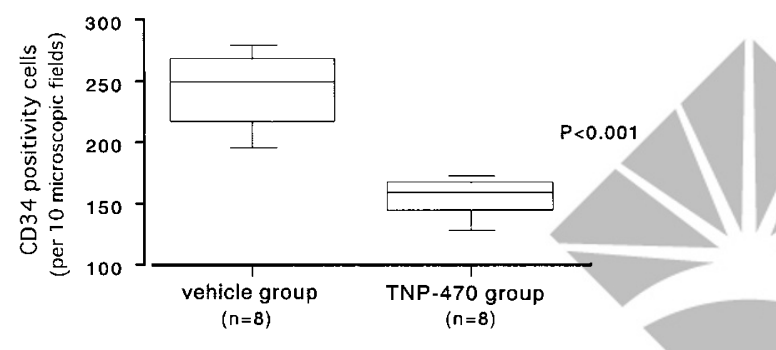

Figure 4.

CD34 positivity ratio in vehicle group and TNP-470 group 2 weeks after implantation. Positivity ratio is calculated and expressed as the number of cells that stained positively for the anti-CD34 pAb per 10 microscopic fields.

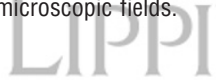

the human VEGF levels of both vehicle and TNP-470 groups were below the detection limit.

\section{Expression and Localization of Human VEGF, FIk-1, and b-FGF in Vehicle Group}

To clarify the relationship between angiogenic growth factors and angiogenesis in SCID mice, we investigated the localization and expression of growth factors (VEGF and b-FGF) and Flk-1, a VEGF receptor. Synovial tissues that were immunohistochemically stained were observed 2 weeks after implantation. In the vehicle group, cells positive for anti-human VEGF were abundant in synovial lining cells and stroma, cells positive for anti-human b-FGF mAbs were abundant in fibroblasts in sublining layer, and cells positive for anti-human Flk-1 mAb were localized in endothelial cells in synovial tissues (Fig. 5).

\section{Angiogenesis in Human Synovial Tissue Grafted SCID Mice 2 and 6 Weeks after Implantation}

Anti-human and anti-mouse CD31 mAbs were used for serial frozen sections of the SCID-HuRAg mice. Two weeks after implantation, cells that stained positively for anti-mouse CD31 mAb were mainly localized in the synovial lining and invaded the subsynovial lining layer in synovial tissues. On the other hand, cells that stained positively for anti-human CD31 mAb were mainly localized in the subsynovial lining layer in human synovial tissues (Fig. 6). Six weeks after implantation, cells that stained positively for anti-mouse CD31 and anti-human CD31 mAbs were clearly divided and none of the cells were double-stained. Based on the immunohistochemical staining with antimouse and anti-human CD31 mAbs, the SCID-HuRAg mice were observed to be surrounded and invaded by blood vessels derived from mouse.

\section{Discussion}

The continuous invasive and destructive growth of synovial tissues is one of the major pathohistologic characteristics of RA patients. The transformedappearing phenotype of synovial lining cells is accompanied by the production of matrix-degrading molecules and the up-regulation and expression of signaling molecules such as growth factors, cytokines, and adhesion molecules (Müller-Ladner et al, 1995). However, the proliferation of these cells being largely dependent on pathologic angiogenesis is observed in various disorders, such as solid tumor growth and metastasis.

There have been several reports that TNP-470 suppresses inflammatory arthritis in models of this disease, such as an adjuvant arthritis rat for Mycobacterium tuberculosis (Peacock et al, 1992, 1995) and a collagen-induced arthritis rat $(\mathrm{CIA})$ from collagen type II rat (CII) (Oliver et al, 1995). Peacock et al (1992) reported that when TNP-470 was administered for a brief period, ranging from 2 to 8 days, development of synovitis was prevented for at least 2 months. One plausible mechanism for this is that angioinhibition in the first 10 dâys in CIA prêcluded pannus formation. This concept is supported by the observation that blood supply is initially observed within the CIA synovia 5 to 7 days after $\mathrm{Cll}$ immunization (Caulfield et al, 1982). Blood supply in the SCID-HuAg mouse in our study is completed within 2 weeks (14 days), and according to CIA models, it is within 18 days after CIA onset (Oliver et al, 1995).

In our study, angiogenesis and synovial cell proliferation are distinctly observed in the vehicle group 2 weeks after implantation; on the other hand, synovial cell proliferation and angiogenesis have been suppressed by treatment with TNP-470. Our results indicate that angiogenesis is involved in synovial cell proliferation. In Figure 6, cells that stained positively for anti-human CD31 mAb are abundant in human synovial tissues and cells that stained positively for anti-mouse CD $31 \mathrm{mAb}$ are abundant in the surrounding human synovial tissues in SCID-HuRAg mice. Whether endothelial cells are derived from human or mouse can be almost clearly distinguished, and some part of the blood vessels derived from mouse were found to invade human synovial tissues. These results confirm that human endothelial cells are fed by blood vessels derived from mouse and the proliferation of human endothelial cells may cross-react with mouse VEGF. Lu et al (2000) reported that HUVEC proliferation is elicited by mouse VEGF, and cDNAs of human 

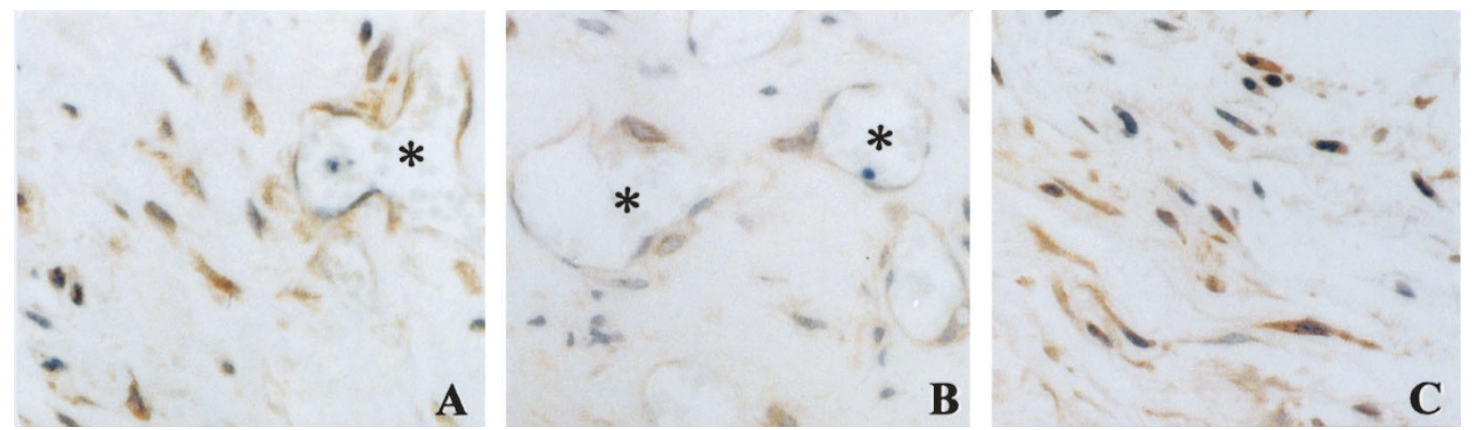

Figure 5.

Immunohistochemical findings for anti-human VEGF, Flk-1, and b-FGF mAbs in SCID-HuAg mice of the vehicle group 2 weeks after implantation. A, B, and C show immunohistochemical staining for anti-VEGF, Flk-1, and b-FGF antibodies in sections from the vehicle group, respectively. Cells positive for anti-VEGF and Flk-1 antibodies were abundant in synovial lining cells and endothelial cells, respectively. On the other hand, cells positive for anti-b-FGF antibody were abundant in fibroblasts in sublining layer without endothelial cells. Original magnification (A to $\mathrm{C}), \times 200 .{ }^{*}$ indicates blood vessel.
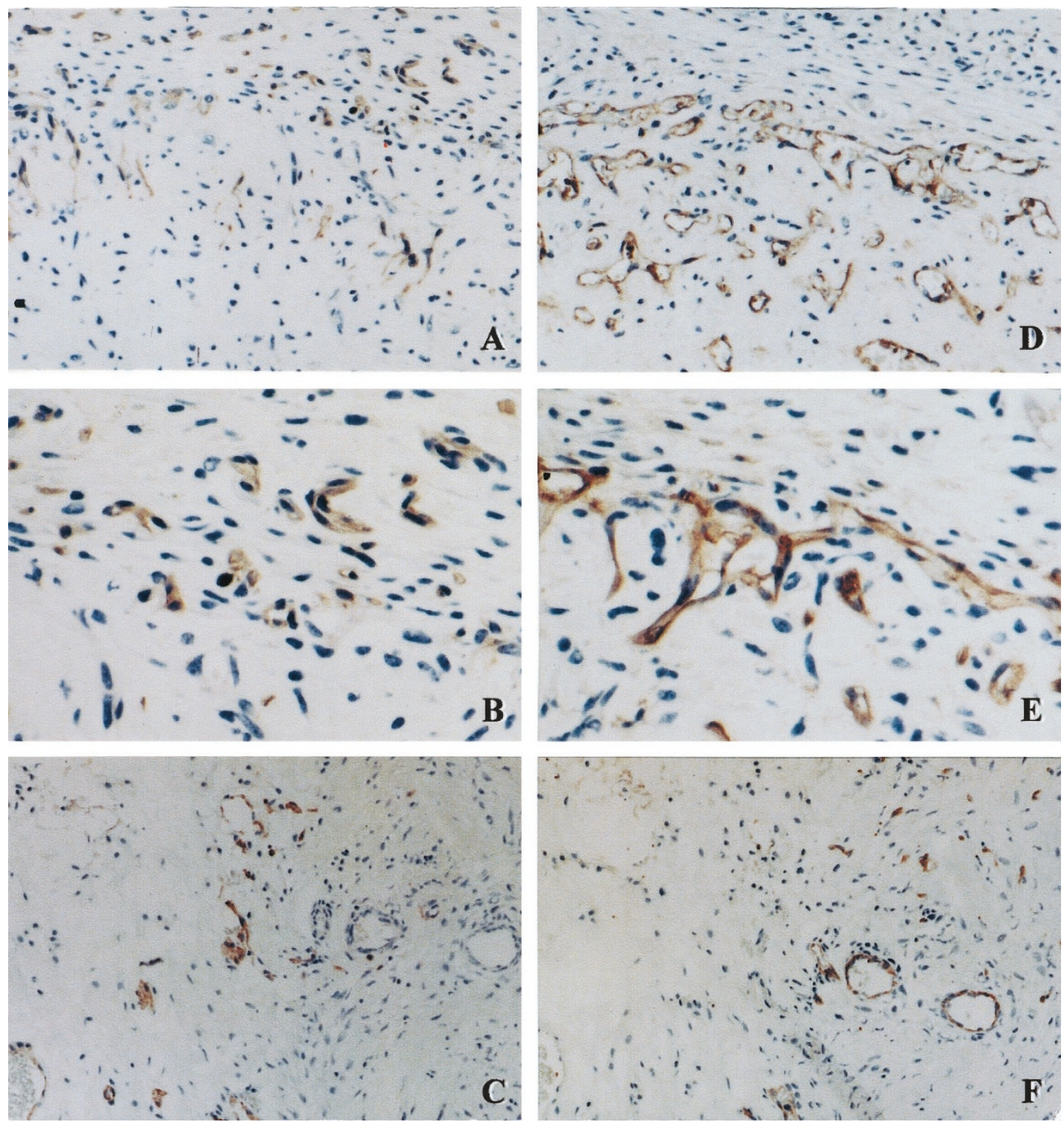

Figure 6.

Immunohistochemical findings for mouse CD31 (A to C) and human CD31 (D to F) mAbs in SCID-HuAg mice of the vehicle and TNP-470-treated groups 2 and 6 weeks after implantation. A and D show immunohistochemical staining (IHS) for anti-mouse and anti-human CD31 mAb in serial sections 2 weeks after implantation (original magnification, $\times 160$ ). $B$ and $E$ show higher magnification of $A$ and $D$ (original magnification, $\times 320$ ). $C$ and $F$ show IHS for these antibodies in serial sections 6 weeks after implantation (original magnification, $\times 160$ ). Human synovial tissues were observed to be surrounded and invaded by blood vessels derived from mouse. 
and murine VEGF show more than $80 \%$ homology (Claffey et al, 1992).

The effect of TNP-470 on the proliferation of cancer cells and HUVECs was examined, and the results suggest that TNP-470 inhibited more strongly the proliferation of endothelial cells than that of cancer cells in vitro (Kawarada et al, 2000; Takatsuka et al, 2000; Wang et al, 2000). The mechanism by which TNP-470 inhibits the proliferation of endothelial cells involves the suppression of cyclin D1 expression in the mid-G1 phase (Abe et al, 1994; Hori et al, 1994). Our results show that the PCNA positivity ratios for synovial cells and endothelial cells in the TNP-470 group were significantly inhibited compared with that in the vehicle group.

On the other hand, angioinhibition may affect endothelial cells directly or indirectly via stimulation/inhibition of cytokines such as thrombospondin, TNF- $\alpha$, IFN- $\alpha 2$, FGF, TGF- $\alpha$, and TGF- $\beta$, or of several angiogenic factors (Folkman and Klagsbrun, 1987; FraterSchroder et al, 1987; Heinmark et al, 1986; Sidky and Borden, 1987; Wiseman et al, 1988). TNP-470 alone or in combination with cyclosporin suppressed VEGF production in CIA (Oliver et al, 1995) and the level of VEGF in the culture supernatant of a TNP-470-treated cell line derived from a carcinosarcoma of the human uterus was significantly lower than that of the control (Emoto et al, 2000).

However, the mechanism underlying the inhibition by TNP-470 is not that of the inhibition of b-FGF and VEGF (Mori et al, 2000). Kawarada et al (2000) reported that TNP-470 did not inhibit VEGF production in vitro. Our results suggest that b-FGF levels in the TNP-470 group were inhibited compared with those in the vehicle group. However, in the vehicle group, b-FGF and VEGF are abundant in synovial tissues as determined using immunohistochemistry (Fig. 5).

The mechanism by which TNP-470 induces apoptosis is not yet clear. Considering that in the vehicle group, apoptosis occurred in regions far from blood vessels in the stroma and apoptosis was not detected near regions with prominent vascularization (data not shown), the inhibition of angiogenesis or hypoxia induces metabolic stress and hypoxia itself also induces apoptosis (Schweiki et al, 1992). At the same time, hypoxia can induce expression of VEGF (Hanahan and Folkman, 1996; Schweiki et al, 1992). However, Wasseberg et al (1999) reported that the signals for angiogenesis by VEGF were abolished by TNP-470, because all vascular parameters were reduced.

Our results indicate that angiogenesis or feeding arteries may play an important role in synovial cell proliferation and cell survival, and inflammatory cells are essential in prolonging the period of inflammatory changes in synovial tissues. We conclude that inhibition of angiogenesis induces the inhibition of synovial cell proliferation in synovial tissues obtained from RA patients, indicating that it is a useful strategy for treating RA.

\section{Materials and Methods}

\section{Human Synovial Tissues}

Human synovial tissues were obtained from eight RA patients diagnosed according to the criteria of the American College of Rheumatology. After we had obtained informed consent from the patients, specimens were obtained during synovectomy of the knee joint. The mean age of the patients was 53.2 years and the mean disease duration was 9.8 years. All of the patients were undergoing prednisolone treatment $(5$ $\mathrm{mg} /$ day). The study was approved by the Human Ethics Committee of Nippon Medical School. Immediately after harvesting, the synovial tissue samples were frozen at $-80^{\circ} \mathrm{C}$ and stored until their engraftment into the SCID mouse.

\section{Transplantation of Human Synovia into SCID Mice}

The frozen synovial tissues were immediately thawed in HBSS warmed at $37^{\circ} \mathrm{C}$, immersed in saline, and irrigated. Briefly, the tissue was cut into small sections (0.3 to $0.4 \mathrm{~g}$ each). The SCID mice were anesthetized with ether. A $1-\mathrm{cm}$ incision was made on the back of each mouse, and 0.3 to $0.4 \mathrm{~g}$ of human synovial tissue was placed subcutaneously, away from the skin incision. Clips were used to close the wound. All surgical procedures were performed under sterile conditions in a laminar flow hood (Jorgensen et al, 1996).

\section{Experimental Design}

Sixteen male SCID Jic mice (BALB/cA-bg, Japan Kurea, Tokyo, Japan), 6 to 9 weeks old and weighing 20.7 to $27.7 \mathrm{~g}$, in which NK activity was suppressed and $T$ and $B$ cells were deficient, were used for establishing the SCID model (Koyanagi et al, 1997). The SCID mice were divided into two groups: the vehicle group and the TNP-470 group, each composed of eight mice. The untreated group received only a vehicle (10\% ethanol/saline) and the treated group received TNP-470 subcutaneously at a dose of $10 \mathrm{mg} / \mathrm{kg}$ body weight in the proximal back every day. Two weeks after implantation, all of the SCID mice were killed. Then, the implanted tissue was removed and blood samples were obtained by heart puncture. In the vehicle group, when angiogenesis and cell proliferation occurred most frequently was investigated according to four time courses: 1, 2, 4, and 6 weeks after implantation.

\section{Preparation and Evaluation of Specimens}

The tissue was cut into two sections: one section was fixed in $10 \%$ neutral formalin and embedded in paraffin for HE staining and immunohistochemical staining. The paraffin sections were cut to a thickness of 3 to 4 $\mu \mathrm{m}$ and were stained with the following antibodies: PCNA mAb (DAKO, Copenhagen, Denmark) and antihuman CD34 pAb (Santa Cruz Biochemicals, Santa Cruz, California). The PCNA antigen, known as cyclin or as an auxiliary protein for DNA polymerase $\delta$, was 
used as a marker of cell growth because its expression increases 2- or 3-fold between early G1 and early $S$ phases (Suzuki et al, 1992). The CD34 antigen is the earliest known marker expressed by human hematopoietic progenitor cells and was also detected in vascular endothelial cells and some fibroblasts (Krause et al, 1994). The other section was fixed in 4\% paraformaldehyde in PBS for 16 to 18 hours. Then, it was immersed in $30 \%(\mathrm{w} / \mathrm{v})$ sucrose in PBS containing $0.02 \%(\mathrm{v} / \mathrm{v}$ ) diethyl pyrocarbonate (Sigma Chemical, St. Louis, Missouri) at $4^{\circ} \mathrm{C}$ for 16 to 18 hours and frozen in an OCT compound at $-80^{\circ} \mathrm{C}$. The frozen sections were cut to a thickness of 5 to $6 \mu \mathrm{m}$, mounted on 3-aminopropyl methoxysilane-coated (silane) slides, and then stained with the following: anti-human CD31 mAb (Chemicon International, Temecula, California) and anti-mouse CD31 mAb (PharMingen, San Diego, California). An endothelial cell-cell adhesion molecule, the platelet endothelial cell adhesion molecule/CD31 antigen, was expressed on the surface of endothelial cells, suggesting that interactions between endothelial cell-cell adhesion molecules are important in angiogenesis (Delisser et al, 1997).

Immunohistochemical staining with these antibodies was performed according to the streptavidinbiotin-peroxidase complex method, using an $A B C$ kit (Nichirei, Tokyo, Japan). The antibodies used were diluted as follows: anti-PCNA mAb,1:150; anti-CD34 pAb, 1:500; anti-human CD31 mAb, 1:200; and antimouse CD31 mAb, 1:200.

\section{Human b-FGF and VEGF Cytokine Assay}

Blood samples were obtained from the vehicle group and the TNP-470 group 2 weeks after implantation (commencement of treatment). The levels of human b-FGF and human VEGF in these samples were measured using appropriate ELISA kits (R and D Systems, Minneapolis, Minnesota).

\section{Immunohistochemical Staining of Human VEGF, Flk-1, and $b-F G F$}

The paraffin sections used were stained with antihuman VEGF mAb, anti-human Flk-1 mAb, and antihuman b-FGF (Santa Cruz). Immunohistochemical staining was performed using antibodies from an $A B C$ kit. VEGF, Flk-1 and b-FGF antibodies were used at 1:200 dilution.

\section{Statistical Analysis}

Statistical evaluation of the difference in the number of positively stained cells in the synovial tissue between the vehicle group and the TNP-470 group was carried out using the Mann-Whitney test for nonparametric samples; $p$ values less than 0.05 were considered to indicate significant differences.

\section{References}

Abe J, Zhou W, Takuwa N, Taguchi J, Kurokawa K, Kumada $\mathrm{M}$, and Takuwa $\mathrm{Y}$ (1994). A fumagillin derivative angiogenesis inhibitor, AGM-1470, inhibits activation of cyclin dependent kinases and phosphorylation of retinoblastoma gene production but not protein tyrosyl phosphorylation or protooncogene expression in vascular endothelial cells. Cancer Res 54:3407-3412.

Brem $\mathrm{H}$ and Folkman $\mathrm{J}$ (1993). Analysis of experimental antiangiogenic therapy. J Ped Surg 28:445-451.

Caulfield JP, Hein A, Dynesius-Trentham R, and Trentham DE (1982). Morphologic demonstration of two stages in the development of type II collagen-induced arthritis. Lab Invest 46:321-343.

Claffey KP, Wilkinson WO, and Spiegelman BM (1992). Vascular endothelial growth factor: Regulation by cell differentiation and activation second messenger pathway. J Biol Chem 267:16317-16322.

Delisser HM, Christofidou-Solomidou M, Strieter RM, Burdick MD, Robinson CS, Wexler RS, Kerr JS, Garlanda C, Merwin JR, Madri JA, and Albelda SM (1997). Involvement of endothelial PECAM-1/CD31 in angiogenesis. Am J Pathol 151:671-677.

Emoto $\mathrm{M}$, Ishiguro $\mathrm{M}$, Iwasaki $\mathrm{H}$, Kikuchi $\mathrm{M}$, and Kawarabayashi K (2000). TNP-470 inhibiys growth and production of vascular endothelial growth factor of uterin carcinosarcoma cells in vitro. Anticancer Res 20:601-604.

Firestein GS (1999). Starving the synovium: Angiogenesis and inflammation in rheumatoid arthritis. J Clin Invest 103: 3-4.

Folkman $\mathrm{J}$ and Klagsbrun M (1987). Angiogenic factors. Science 235:442-447.

Frater-Schroder M, Risau W, Hallmann R, Gautschi P, and Bohlen P (1987). Tumor necrosis factor type $\alpha$, a potent inhibitor of endothelial cell growth in vitro, is angiogenic in vivo. Proc Natl Acad Sci USA 84:5277-5281.

Geiler T, Kriegsmann J, Keyszer GM, Gay RE, and Gay S (1994). A new model rheumatoid arthritis generated by engraftment of rheumatoid synovial human cartilage into SCID mice. Arthritis Rheum 37:1664-1671.

Hanahan D and Folkman $\mathrm{J}$ (1996). Patterns and emerging mechanisms of the angiogenic switch during tumorigenesis. Cell 86:353-364.

Heinmark RL, Twardzik DR, and Schwartz SM (1986). Inhibition of endothelial regeneration by type-beta transforming growth factor from platelets. Science 233:1078-1080.

Hori A, Ikeyama S, and Sudo K (1994). Suppression of cyclin D1 expression by the angiogenesis inhibitor TNP-470(AGM$1470)$ in vascular endothelial cells. Biochem Biophys Res Commun 204:1067-1073.

Ingber D, Fujita T, Kishimoto S, Sudo K, Kanamaru T, Brem $\mathrm{H}$, and Folkman $\mathrm{J}$ (1990). Synthetic analogues of fumagillin that inhibit angiogenesis and suppress tumor growth. Nature 348:555-557.

Jorgensen C, Couret I, Hellier I, Bologna C, Canovas F, Brochier J, Reme T, and Sany J (1996). In vivo migration of radiolabelled lymphocytes in rheumatoid synovial tissue engrafted in SCID mice: Implication of beta2 and beta7-integrin. J Rheumatol 23:32-35.

Kawarada Y, Ishikura H, Kishimoto T, Saito K, Takahashi T, Kato H, and Yoshiki T (2000). Inhibitory effects of the antiangiogenic agent TNP-470 on establishment and growth of 
hematogenous metastasis of human pancreatic carcinoma in SCID beige mice in vivo. Pancreas 15:251-257.

Koch AE (1998). Angiogenesis-implications for rheumatoid arthritis. Arthritis Rheum 41:951-962.

Koyanagi Y, Tanaka Y, Kira J, Ito M, Hioki K, Misawa N, Kawano Y, Yamasaki K, Tanaka R, Kumazawa Y, and Yamamoto N (1997). Primary human immunodeficiency virus type 1 viremia and central nervous system invasion in a novel hu-PBL-immunodeficient mouse strain. J Virol 71:24172424.

Krause DS, Ito T, Fackler MJ, Smith OM, Collector MI, Sharkis SJ, and May WS (1994). Characterization of murine CD34, a marker for hematopoietic progenitor and stem cells. Blood 84:691-701.

Locigno R, Antonine N, Bours V, Daukandt M, Heinen E, and Castronovo V (2000). TNP-470, a potent angiogenesis inhibitor, amplifies human $\mathrm{T}$ lymphocyte activation through an induction of nuclear factor- $\kappa \mathrm{B}$, nuclear factor-AT, and activation protein-1 transcription factors. Lab Invest 80:13-21.

Lu J, Kasama T, Kobayashi K, Yoda Y, Shiozawa F, Hanyuda M, Negishi M, Ide H, and Adachi M (2000). Vascular endothelial growth factor expression and regulation of murine collagen-induced arthritis. J Immunol 164:5922-5927.

Matsuno H, Sawai T, Nezuka T, Uzuki M, Tsuji H, Nishimoto $\mathrm{M}$, and Yoshizaki K (1998). Treatment of rheumatoid synovitis with anti-reshaping human interleukin-6 receptor monoclonal antibody. Arthritis Rheum 41:2014-2021.

Mori J, Haisa M, Naomoto Y, Takaoka M, Kimura M, Yamatsuji T, Notohara K, and Tanaka N (2000). Suppression of tumor growth and downregulation of platelet-derived endothelial cell growth factor/thymidine phosphorylase in tumor cells by angiogenesis inhibitor TNP-470. Jpn J Cancer Res 91:643-650.

Müller-Ladner U, Kriegsmann J, Gay RE, and Gay S (1995). Oncogenes in rheumatoid arthritis. Rheum Dis Clin North Am 21:675-689.

Nagashima M, Asano G, and Yoshino S (2000). Imbalance production between vascular endothelial growth factor and endostatin in patients with rheumatoid arthritis. J Rheumatol 27:2339-2342.

Nagashima M, Yoshino S, Ishikawa T, and Asano G (1995). Role of vascular endothelial growth factor in angiogenesis of rheumatoid arthritis. J Rheumatol 22:1624-1629.

Oliver SJ, Cheng TP, Banquerigo ML, and Brahn E (1995). Suppression of collagen-induced arthritis by an angiogenesis inhibitor, AGM-1470 in combination with cyclosporin: Reduction of vascular endothelial growth factor (VEGF). Cell Immunol 166:196-206.

Peacock DJ, Banquerigo ML, and Brahn E (1995). A novel angiogenesis inhibitor suppresses rat adjuvant arthritis. Cell Immunol 160:178-184.
Peacock DJ, Banquerigo ML, and Brahn E (1992). Angiogenesis inhibition suppress collagen arthritis. J Exp Med 175: 1135-1138.

Rendt KE, Barry T, Jones DM, Richter CB, McCachren SS, and Haynes BF (1993). Engraftment of human synovium into severe combined immune deficient mice: Migration of human peripheral blood T cells to engrafted human synovium and to mouse lymph nodes. J Immunol 151:7324-7336.

Sack U, Kuhn H, Ermann J, Kinne RW, Vogt S, Jungmichel D, and Emmrich $F$ (1994). Synovial tissue implants from patients with rheumatoid arthritis cause cartilage destruction in knee joints of SCID.bg mice. J Rheumatol 21:10-16.

Sack U, Kuhn H, Kaempfer I, Genest M, Arnold S, Pfeiffer G, and Emmrich $F$ (1996). Orthotopic implantation of inflamed synovial tissue from RA patients induces a characteristic arthritis in immunodeficient (SCID) mice. J Autoimmun 9:5158.

Schweiki D, Itin A, Soffer D, and Keshet E (1992). Vascular endothelial growth factor induced by hypoxia may mediate hypoxia-initiated angiogenesis. Nature 359:843-845.

Sidky YA and Borden EC (1987). Inhibition of angiogenesis by interferons: Effects on tumor and lymphocyte-induced vascular responses. Cancer Res 47:5155-5161.

Suzuki K, Kato R, and Kawaoi A (1992). Immunohistochemical demonstration of proliferating cell nuclear antigen (PCNA) in formalin-fixed, paraffin-embeded sections from rat and human tissues. Acta Histochem Cytochem 25:13-21.

Takatsuka S, Yamada N, Sawada T, Ogawa Y, Maeda K, Ohira M, Ishikawa T, Nishino H, Seki S, and Hirakawa-YS Chung K (2000). Contribution of angiogenesis to the progression of colon cancer: Possible inhibitory effect of angiogenesis inhibitor TNP-470 on tumor growth and hepatic metastasis. Int J Oncol 17:253-258.

Wang J, Lou P, and Henkin J (2000). Selective inhibition of endothelial cell proliferation by fumagillin is not due to differential expression of methionine aminopeptidases. J Cell Biol 77:465-473.

Wasseberg E, Hedborg F, Sköldenberg E, Stridsberg M, and Christofferson R (1999). Inhibition of angiogenesis induces chromaffin differentiation apoptosis in neuroblastoma. Am J Pathol 154:395-403.

Wiseman DM, Polverini PJ, Kamp DW, and Leibovich SJ (1988). Transforming growth factor-beta $(\operatorname{TGF} \beta)$ is chemotactic for human monocytes and induces their expression of angiogenic activity. Biochem Biophys Res Commun 157: 793-800. 